\section{Liquor-natürliche Killerzellen}

T. O. Kleine

Institut für Laboratoriumsmedizin und Pathobiochemie, Molekulare Diagnostik Standort Marburg Referenzlabor für Liquordiagnostik, UKGM Universitätsklinikum Gießen und Marburg, Marburg, Deutschland

Synonym(e) $\mathrm{CD}_{16} 6^{+} 56^{+} 3^{-}$-Zellen in CSF; NK-Zellen in Liquor cerebrospinalis (CSF)
Englischer Begriff CSF natural killer cells

Definition Liquor-NK-Zellen suchen im Rahmen der Immunüberwachung in Zentralnervensystem (ZNS) bzw. CSF Zellen mit viralen oder bakteriellen Pathogenen bzw. aggregierte IgG, um diese $\mathrm{zu}$ zerstören; \ Natural-KillerLymphozyt (s. a. > Liquor cerebrospinalis). 